\title{
Defining the learning curve for minimally invasive segmentectomy
}

\author{
Benny Weksler, MD, MBA
}

From the Division of Thoracic Surgery, University of Tennessee Health Science Center, Memphis, Tenn. Disclosures: Dr Weksler is a proctor for Intuitive Surgical Inc

Received for publication June 27, 2018; revisions received June 27, 2018; accepted for publication June 28, 2018; available ahead of print Aug 18, 2018

Address for reprints: Benny Weksler, MD, MBA, Division of Thoracic Surgery, University of Tennessee Health Science Center, 1325 Eastmoreland Ave, Ste 460, Memphis, TN 38104 (E-mail: bweksler@uthsc.edu).

J Thorac Cardiovasc Surg 2018;156:2004-5

$0022-5223 / \$ 36.00$

Copyright (C) 2018 by The American Association for Thoracic Surgery

https://doi.org/10.1016/j.jtcvs.2018.06.065

In thoracic surgery, a plethora of new technologies and procedures have been introduced over the past 15 to 20 years, including minimally invasive lobectomy and segmentectomy, minimally invasive esophageal surgery, minimally invasive mediastinal surgery, robotic surgery, peroral endoscopic myotomy, endobronchial ultrasound, and navigational bronchoscopy. It is a given that technology will continue to evolve, and surgeons will need to learn new procedures throughout the course of their careers to offer the best treatment options for their patients. In the midst of this explosion of new procedures, it appears that teaching and credentialing have been lagging. The definition of competency and how many cases are needed to reach competency have been poorly defined. To muddy the issue further, there are few studies that offer rigorous analyses of the learning curves for thoracoscopic procedures. For example, the number of cases needed to conquer the learning curve of video-assisted thoracoscopic surgery (VATS) lobectomy has been estimated to be between 30 and 60 cases. This was estimated to be only $\sim 20$ cases for robotic lobectomy, but the estimate was based on loose scientific criteria. ${ }^{1-3}$ There were no studies of the learning curve for VATS segmentectomy.

Hamada and colleagues ${ }^{4}$ report on the learning curve for VATS segmentectomy. Data were prospectively collected on 252 consecutive patients undergoing VATS segmentectomy and analyzed retrospectively. One leading surgeon performed 153 procedures $(61 \%)$ and 12 other surgeons, including 9 trainees, performed the remaining segmentectomies. The second busiest surgeon performed 38 cases $(15 \%)$ and the third 28 cases $(11 \%)$; the remaining 10 surgeons performed just 33 total cases $(13 \%)$-fewer than 4 cases per surgeon. The authors classified the difficulty level of the segmentectomy, and the leading surgeon, as expected, took on more difficult cases than the other surgeons. Operative time was used as a surrogate for competency and analyzed using cumulative sum analysis, allowing the determination of 3 distinct learning phases: initial learning, increased competency, and finally mastery of the

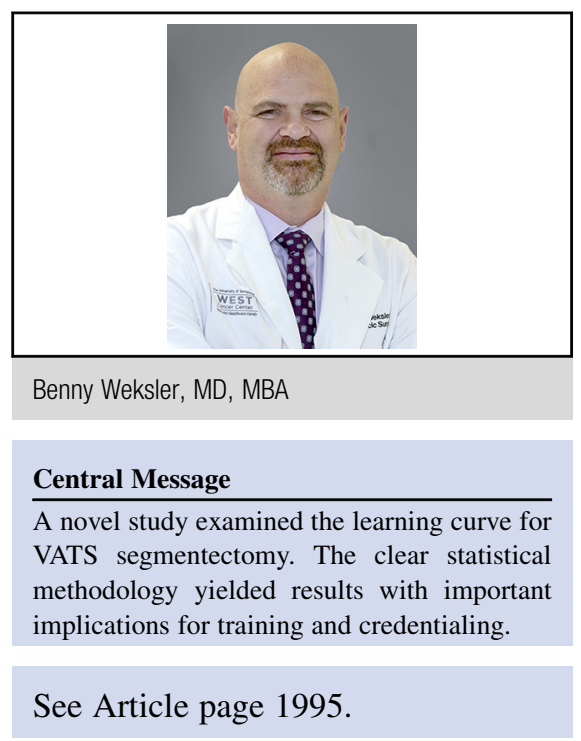

procedure. When the operative times of all 13 surgeons were examined together to determine the learning curve for the department, the second phase (increased competency) was reached after 61 cases, and the final phase (mastery) was achieved after 84 cases. There were significant differences in operative time and bleeding between the initial phases and the final phase (mastery), and a trend toward shorter hospital length of stay. When the learning curves of the leading surgeon and the remaining 12 surgeons were analyzed separately, excluding the most difficult segmentectomies that the leading surgeon performed significantly more often that the other surgeons, the leading surgeon achieved phase 3 (mastery of the procedure) after 32 cases, and the other surgeons together achieved phase 3 after 38 cases.

These data are relevant because of the clear statistical methodology and objective determination of the learning curve. Although the authors claim that the learning curve can be conquered in a relatively short time, according to their data the leading surgeon performed on average $10 \mathrm{seg}$ mentectomies a year, excluding the most difficult cases. To reach 18 cases to conquer the learning curve and 32 cases to achieve mastery, he needed 2 and 3 years, respectively. The remaining surgeons averaged 8 to 9 cases per year and required 28 cases $(\sim 3$ years) for increased competence and 38 cases ( $\sim 4.5$ years) to mastery—certainly not a short time. Additionally, 10 surgeons performed, on average, fewer than 4 cases each, so the data on the learning curve of other surgeons as a group should be viewed with some 
suspicion. Analysis of the learning curves of the secondand third-most experienced surgeons may have been informative.

It is also unclear what role the leading surgeon played in teaching the other surgeons and how this influenced their learning curve. A recent article suggest that proctoring can reduce the number of cases needed to achieve proficiency in robotic esophagectomy from 70 to just $24 .^{5}$ Other important questions when evaluating the learning curve for a new surgical procedure include the role of previous operative experience in learning a new procedure and the role of simulation in increasing competency. ${ }^{6,7}$ Nonetheless, this is an important article on the learning curve for VATS segmentectomy, which is slowly becoming the standard of care for lung cancers smaller than $2 \mathrm{~cm}$. These data can and should be used by training programs and credentialing committees in establishing standards to ascertain good outcomes in thoracic surgery.

\section{References}

1. Zhao H, Bu L, Yang F, Li J, Li Y, Wang J. Video-assisted thoracoscopic surgery lobectomy for lung cancer: the learning curve. World J Surg. 2010;34:2368-72.

2. McKenna RJ Jr. Complications and learning curves for video-assisted thoracic surgery lobectomy. Thorac Surg Clin. 2008;18:275-80.

3. Meyer M, Gharagozloo F, Tempesta B, Margolis M, Strother E, Christenson D. The learning curve of robotic lobectomy. Int J Med Robot. 2012;8:448-52.

4. Hamada A, Oizumi H, Kato H, Suzuki J, Nakahashi K, Sho R, Sadahiro M. Learning curve for port-access thoracoscopic anatomic lung segmentectomy. J Thorac Cardiovasc Surg. 2018;156:1995-2003.

5. van der Sluis PC, Ruurda JP, van der Horst S, Goense L, van Hillegersberg R. The learning curve for robot-assisted minimally invasive thoracoscopic esophagectomy: results from 312 cases. Ann Thorac Surg. 2018;106:264-71.

6. Grantcharov TP, Bardram L, Funch-Jensen P, Rosenberg J. Learning curves and impact of previous operative experience on performance on a virtual reality simulator to test laparoscopic surgical skills. Am J Surg. 2003;185:146-9.

7. Grantcharov TP, Kristiansen VB, Bendix J, Bardram L, Rosenberg J, FunchJensen P. Randomized clinical trial of virtual reality simulation for laparoscopic skills training. Br J Surg. 2004;91:146-50. 